\title{
A Qualitative Study for Perceptions Toward Successful Aging Among Older Korean Immigrants in the United States
}

\author{
Jaewon Lee, PhD, MSW \\ Assistant Professor, Dept. of Social Work, \\ California State University Bakersfield \\ Bakersfield, California, USA \\ Tel: 1-661-654-6543Ｅ-mail: jlee88@csub.edu
}

Received: April 6, 2018 Accepted: May 6, 2018 Published: May 8, 2018

doi:10.5296/ijsw.v5i2.12961 URL: http://doi.org/10.5296/ijsw.v5i2.12961

\begin{abstract}
A qualitative study was designed as an attempt to overcome the limitations of previous studies of successful aging, which included biased sample population, ignorance of subjective perception of successful aging, and a restrictive definition. The purpose of this study was to explore older immigrants' perceptions toward successful aging and to indicate the important predictors to determine successful aging. In addition, this study aimed to identify significant factors influencing willingness to become successful agers among older immigrants in the United Sates. The research design was a cross-sectional key informant interview. One hundred and two $(\mathrm{N}=102)$ older Koreans in Los Angeles, CA, participated in this study. Interestingly, their children's successful life was one of the heavily influential factors to become a successful ager among them. Implications are directed to social work researchers and practitioners to help educate the ethnic older adults in the community on the social and behavioral importance of the positive aspects of aging such as successful aging and healthy aging to increase the chance of longevity.
\end{abstract}

Keywords: Successful aging, Older Korean immigrants, Qualitative research

\section{Introduction}

Rowe and Kahn's longitudinal study developed the theory of successful aging, which has been considered one of the best conceptualized theories among the studies on aging. However, there have been controversies on the theory for such reasons as the restricted subjectivity on the perceptions toward successful aging and the limited sample population for the study participants. Therefore, further study is needed to investigate the subjective perceptions on 
successful aging and to focus on ethnic minority populations who may be more vulnerable due to their lower socioeconomic status and cultural differences.

This qualitative study aims to examine what successful aging means to ethnic older immigrant members of this diverse society. Compared to Rowe and Kahn's study, this study of perceptions toward successful aging among older Korean immigrants has a different sample population from a different region, Los Angeles, California, with different cultural backgrounds and socioeconomic status as well as different perspectives on aging. More specifically, this study explores the older Korean immigrants' perceptions toward successful aging and indicates the important predictors to determine successful aging among them. The purpose of this study is to explore and identify significant factors influencing willingness to become successful agers among older Korean immigrants in the United Sates. Since members of this ethnic older immigrant group have different cultural backgrounds, history, perceptions toward aging, and perspectives of life and death, different responses related to predictors and factors of successful aging are expected, expanding the results of the previous studies. Hence, studying successful aging among older Korean immigrants in the United States is significant not only to understand the population better but also to improve an individual's quality of later life, which can in turn ensure a healthier community and society.

\subsection{Older Koreans in the United States}

For more than a century, the number of Korean immigrants in the U.S. increased dramatically, from only a couple hundred in early 1900 to currently over 2.5 million (US Census Bureau, 2012). The City of Los Angeles and the New York City area have the largest number of Korean immigrants, which is estimated at over a million and half in those two areas. These two large metropolitan areas are followed by Atlanta, Washington D.C, Chicago, Seattle, Dallas, and Houston with over 100,000 to 200,000 Koreans in each city, each with large Korean communities (Lee, 2007; Oh, Zhou, Kreps, \& Kim, 2014).

There have been a few number of studies to investigate the population's quality of life as they have been placed on the marginal area due to their lower socioeconomic status, poor physical and mental health, and lack of resources for socializations. In addition to the problems from their natural aging process, the majority of older Korean immigrants experience acculturative stress when they encounter the social, cultural, and linguistic barriers in a new country (Berry, 2003; Choi \& Thomas, 2009; Lee, 2007). The stress is often associated with biopsychosocial problems such as rapid deterioration of physical functions, mental health problems, and social isolation (Han, Kim, Lee, Pistulka, \& Kim, 2007; Jang, Kim, \& Chiriboga, 2006). According to a research study on acculturation and depression among seven older ethnic minorities from foreign countries in the United States, older adults from South Korea were identified as the population experiencing the most serious psychological distress (Tseng et al., 2010).

The Asian American Federation's (AAF) study of 'Growing Older' (2003), based on interviews of 407 older Asian immigrants in the New York Metropolitan area (105 Chinese, 100 Koreans, 100 Indians, and 102 other Asians) reported that over $70 \%$ of the Korean participants responded that they had experienced rapid deterioration of their physical health after their relocation (over $80 \%$ from the AAF survey responded that they moved to the U.S. after the late 1990s). In addition, over $40 \%$ of the Korean study participants reported having symptoms of depression and anxiety after their relocation to the United States (AAF, 2003). 
Over $80 \%$ of them responded as having feelings of social isolation due to their hardship of communication in English and cultural differences. Furthermore, over 30\% of them stated that they lived under the poverty line (household income less than $\$ 20,444$ per year) due to a lack of financial resources, which correlates to less confidence in social interaction with others.

In sum, older Korean immigrants are experiencing extra biopsychosocial problems such as psychological distress, rapid deterioration of physical health, and social isolation. Those problems may be the result from relocation to a new country with different culture and language, financial hardships due to a lack of income resources, and cultural challenges related to the language barrier in addition to their natural aging process (Choi \& Thomas, 2009; Lee, 2007). Therefore, older Korean immigrants are at a greater risk of being marginalized due to lower socioeconomic status, health problems, and acculturative stress (Hooyman \& Kiyak, 2011).

\section{Literature Review}

\subsection{Overview of Successful Aging Theory}

A large number of studies have focused on theories of how to age well (Atchley, 1989; Baltes \& Baltes, 1990; Cumming \& Henry, 1961; Larson \& Phelan, 2002; Li et al., 2006; Liang \& Luo, 2012; Rowe \& Kahn, 1997). Among those studies, Rowe and Kahn's theory of successful aging has been assessed as one of the best-conceptualized healthy aging theory over the past decade (Chung \& Park, 2008; Depp \& Jeste, 2006; Ferri, James, \& Pruchno, 2009).

Rowe and Kahn (1997) defined successful aging as "an avoidance of disease and disability, maintenance of high physical and cognitive functioning, and engagement with social and productive activities" (p. 439). If an older adult displayed no or few diseases and health-related disabilities, maintained high physical and cognitive functions, and sustained social and productive activities, that older adult is a "successful ager" applying (Ferri, James, \& Pruchno, 2009). Rowe and Kahn's theory has been considered the most representative for defining successful aging, and it has been one of the most influential in the field of gerontology (Depp \& Jeste, 2006; Ferri, James, \& Pruchno, 2009; Maki, 2005; Nagalingam, 2007; Victor, 2004).

The theory was generated from the MacArthur Studies of Successful Aging, which was conducted from 1988 to 1996 as a longitudinal study. The study was initiated from the simple assumption that agers with the least health-related issues are successful agers. This study and the accompanying theory of successful aging have been assessed as some of the most influential conceptualizations of healthy aging.

\subsection{Theory Controversies}

The theory has been controversial based on its weaknesses regarding the primary study's limited access to the sample populations and recruiting regions, and the lack of representation of sample characteristics. Beyond these two points, the theory has been criticized based on its emphasis on the maintenance of physical and cognitive functions. The majority of older adults who are given the high incidence and prevalence of disease that are common in later life can be misleading to the criteria of unsuccessful agers (Dillaway \& Byrnes, 2009). 
According to McLaughlin et al.'s study from 2009, no greater than $11.9 \%$ of older adults in the USA were aging successfully (prevalence estimates from a national sample of older adults). The researchers used the secondary data from the Health and Retirement Study (HRS), and the prevalence of successful aging was calculated for older adults aged over 65 years at four time points: 1998, 2000, 2002, and 2004. Surprisingly, few older adults (only $11.9 \%$ of older adults in the USA) met the criteria of Rowe and Kahn's definition of successful aging. Unsurprisingly, the rate of successful aging was generally lower for those of advanced age, the male gender, and lower socioeconomic status (McLaughlin, Connell, Heeringa, Li, \& Roberts, 2009).

As mentioned earlier, the theory focuses more on the health status of older adults, and the scientists conducting the study predicted that older adults who maintain active and reciprocal relationships with their social environment would likely be aging more successfully. However, they ignored the subjective perceptions of successful aging among older populations. Older adults' subjective perceptions of successful aging can bring up different factors and predictors of determining whether they are aging successfully or not (Depp \& Jeste, 2006; Dillaway \& Byrnes, 2009; Knight \& Ricciardelli, 2003; Phelen, Anderson, LaCroix, \& Larson, 2004; Larson \& Phelan, 2002).

\subsection{Studies on Successful Aging}

A considerable number of studies have been conducted on successful aging. However, only two studies regarding successful aging among older ethnic minorities in the United States were found in the California State University Library database and online search engines such as Google Scholar: "Relationship Between Spirituality and Successful Aging Among Older Minority Women" (Maki, 2005) and "Successful Aging and the Chinese-American Elder" (Victor, 2004). Both studies were based on qualitative research methods including up to 20 in-depth interviews regarding the perceptions toward successful aging among older minorities in the United States. No studies focusing on the successful aging of older Korean immigrants were found, hence literature review for this study concentrates on other relevant studies on successful aging in the United States and other countries.

Numerous studies (Chung \& Park, 2008; Cernin, 2009; Tate, Lah, \& Cuddy, 2003; Larson \& Phelan, 2002; Li et al., 2006; Liang \& Luo, 2012; Maki, 2005; Nagalingam, 2007; Victor, 2004) have employed the theories of successful aging as their main conceptual framework in gerontological research studies in the United States and other countries such as China, Singapore, and Latin American countries. These studies in other countries have displayed some commonalities in the components of successful aging, indicating that these ideas can be important factors in determining if the older minority populations in the United States are successful agers or not.

However, they have also suggested other perceptions that should be added to these criteria (Depp \& Jeste, 2006; Ferri, James, \& Pruchno, 2009; Tan, Ward, Ziaian, 2011). For example, a qualitative study of older Indian adults in Singapore reported that the population selected health status was the most important factor in influencing successful aging, but religious activities, financial resources, and intergenerational relationships were equally important to them (Nagalingam, 2007). Although it is not expansive, the literature presents a framework as to how the theories of successful aging can be fitted to various populations. 
According to Larson and Phelan's study (2002), there are four dimensions of conditions to determine their successful aging: 1) physical, 2) social, 3) functional, and 4) psychological, and more than $75 \%$ of the participants of the study responded that those four dimensions were the most important factors to determine successful aging (Larson \& Phelan, 2002). In addition, the item "being able to take care of myself until close to the time of my death" (from the functioning domain) was rated most important to successful aging by the highest percentage of older adults in the cohort (Larson \& Phelan, 2002). In contrast, the items "living a long time" and "being able to work in paid or volunteer activities after usual retirement age" were rated "not at all important" by the largest proportion of participants (Larson \& Phelan, 2002). Their recommendation for future research was to consider the definitions of aging from the individual's perspectives (Dillaway \& Byrnes, 2009; Larson \& Phelan, 2002).

Strawbridge, Wallhagen, and Cohen (2002) similarly suggested understanding older persons' own criteria. They called the choice of the term "successful" problematic, as it implies that there are winners and losers. Their study found that while a little more than half the participants reported themselves to be aging successfully, only $18.8 \%$ could be classified as such according to Rowe and Kahn's criteria (Strawbridge, Wallhagen, \& Cohen, 2002).

Continuing with this theme of a self-report or a subjective definition, Tate, Lah, and Cuddy (2003) analyzed a 1996 survey of elderly Canadian men. Twenty themes emerged from the open-ended question, "What is your definition of successful aging?" The top three answers, each appearing in over $20 \%$ of the responses, were good health, satisfaction/happiness, and keeping active. To the question, "Would you say you have aged successfully?", more than $83 \%$ responded "yes" without qualification (Tate, Lah, \& Cuddy, 2003).

Another study from an Asian country examines "Successful Aging in Shanghai, China: Definition, Distribution and Related Factors" (Li et al., 2006), which was a part of the Shanghai Successful Aging Project, a cross-sectional study to explore perceptions toward successful aging among older adults in the same city. The researchers found that 1) socio-demographic variables are negatively correlated with rates of successful aging; 2) higher educational level and marriage status are related to a higher rate of successful aging; 3) health-related behaviors such as eating habits and quality of sleeping are positively correlated with successful aging; and 4) the more leisure activities, the higher probability of successful aging. Further, the researchers found that life satisfaction and negative life events were correlated with successful aging.

Also, "A Comparison of Self-rated and Objectively Measured Successful Aging in an Urban Sample of African American Older Adults" is a study that investigated successful aging for the African American population (Cernin, 2009). The researcher analyzed 67 African American individuals who were divided into successful and non-successful aging groups based on Rowe and Kahn's objective criteria. The same group was also divided into successful and non-successful aging groups based on self-rated success.

The results showed that self-rated successful aging is best predicted by being active, whereas objectively measured successful aging is best predicted by demographic characteristics and cognition. However, reading ability, an index of education quality, and the relationship between education and cognition for objective successful aging are also important predictors 


\section{Macrothink}

International Journal of Social Work

ISSN 2332-7278

2018, Vol. 5, No. 2

for the population's successful aging. Additionally, objective successful aging is more related to quantity and quality of education than it is to health behaviors, whereas self-rated successful aging is related to a wider variety of variables, including social engagement as well as health-related behaviors.

\section{Methodology}

\subsection{Research Design and Sampling Methods}

This study was designed as a qualitative research project using key informant interview with open-ended questions concerning the important factors that determine successful aging. The primary purposes of the interview were; 1) to identify factors that influence achieving successful aging among the older Korean immigrants in the United States; 2) to explore the factors and predictors that determine successful aging among the population; and 3) to compare attitudes and tendencies regarding successful aging among the population in the United States.

One hundred and two participants $(\mathrm{N}=102)$ who were attending two different Adult Day Health Care Centers in Los Angeles, California, participated in the interview. The interview was voluntary, and the informed consent form that was approved by the IRB of the California State University was given to all the participants. The purpose of the study and detailed information were explained to the participants prior to the interview.

Table 1. Demographic characteristics $(\mathrm{N}=102)$

\begin{tabular}{lll}
\hline Demographic Characteristics & Group & Number (\%) \\
\hline Gender & Male & $39(38.2)$ \\
& Female & $63(61.6)$ \\
Age & $71-80$ & $27(26.5)$ \\
& $81-90$ & $68(67.6)$ \\
& $91-$ & $6(5.9)$ \\
Marital & Married & $39(38.2)$ \\
& Divorce & $6(5.9)$ \\
& Separated & $4(3.9)$ \\
& Widowed & $52(51.0)$ \\
& Missing & $1(1.0)$ \\
& & $4(3.9)$ \\
Education & No education & $46(45.1)$ \\
& Elementary & $15(14.7)$ \\
& Middle School & $15(14.7)$ \\
\hline
\end{tabular}




Group
Associate Degree
Bachelor's Degree
Graduate School

Occupation

Volunteer

Financial Hardship

Lack of Food Money

Yes

No

No

No

Income (SSI)

Living With Whom

Spouse

Children

Alone

Nursing Home

Missing

How many family members

2

3

4

Missing

Senior APT

Own
$102(100)$

Number (\%)

5 (4.9)

$16(15.7)$

$1(1)$

$102(100)$

$102(100)$

$1(1.0)$

101 (99.0)

1 (1.0)

101 (99.0)

$102(100)$

98 (96.1)

4 (3.9)

35 (34.3)

7 (6.9)

47 (46.1)

12 (11.8)

1 (1.0)

49 (48.0)

37 (36.3)

2 (2.0)

2 (2.0)

12 (11.8)

65 (63.7)

3 (2.9) 


\begin{tabular}{lll}
\hline Demographic Characteristics & Group & Number (\%) \\
\hline & Rent & $21(20.6)$ \\
& Nursing Home & $13(12.7)$
\end{tabular}

This study used the convenience sampling method, which is a non-probability voluntary response sampling method (Creswell, 2009). The participants were older Korean immigrants in the United States who were 60 years old or more, regardless of having specific physical diseases or disabilities, gender, marital status, income, occupation, and living with someone or living alone. Eligibility criteria required for this study were the following: 1) able and willing to provide informed consent, 2) cognitively stable to understand questions in the survey, and 3) aged 60 years or older.

Initially, the executive directors of the two Adult Day Health Care Centers were asked to participate in this dissertation study. Follow-up contacts with the administrators of the centers were made and both authorized program directors agreed to join this study and recruit voluntary participants to take the survey. Contacts for visiting the agencies were made with the program directors of the agencies, and the arrangements were made for in-person visits with verbal consent. One hundred percent of onsite surveys were administered in the agencies.

\subsection{Data Collection and Procedures}

The participants who responded to this study were interviewed by the researcher. Before initiating the interview, a Korean version of the consent form including an introductory letter to provide a better understanding of the purpose of the study was distributed to the participants. The letter explained the need for and importance of a successful aging study in social work as well as the purpose of the study. In addition, it described the participants' right to stop their participation or to refuse to answer the questions in the survey and included a confidentiality clause.

Two consent forms were provided to the participants—one form to turn in to the researcher and the other one to take home. Approximately 30 minutes was estimated for the completion of the onsite in-dept structured interview. However, it took more than 30 minutes, up to one hour, for a respondent to complete the set of questions due to the older participants' slowness to understand the questions. This was not a result of their cognitive ability nor language problem, and spending more time with the respondents was beneficial to the researcher for gathering better information about their attitudes and perceptions toward successful immigrant life.

\subsection{Data Analysis}

The data analysis included consideration of demographic variables such as age, gender, and marital status. Due to the homogeneity of the Korean population, ethnicity was excluded from the demographic variables to be considered. Open-ended questions regarding the participants' subjective perceptions toward successful aging and the influential components of aging successfully were provided and analyzed by rank order. The researcher used field 
notes while surveying older Korean immigrants. The field notes described the general observation of the participants' mood, behaviors, and interaction with the researcher during the survey, which consisted of open-ended questions concerning the important factors that determine successful aging. The field notes were helpful for analyzing the respondents' answers to the open-ended questions.

Coding was done according to the themes evident in the words and sentences in the conversation revealing their subjective perception of successful aging as well as the overall interview process. The questions and the responses from the open-ended questions were back-translated into English to increase the accuracy of the language equivalence, and both versions were checked by bilingual faculty in the Department of Social Work and Education at the California State University Bakersfield. The researcher's subjective thoughts or feelings about the content of the interview might have been included in the notes, but they were excluded in the analysis in order to prevent biased results. The respondents were screened for cognitive ability by the researcher's professional decision prior to their participation in this study.

\section{Results}

\subsection{Important Factors and Predictors Determining Successful Aging}

The older Korean participants responded to the question "In your opinion, what are important factors (or predictors) that determine successful aging?" Each participant was able to address at most three responses to this question. Therefore, a total of 306 answers were received for this open-ended question. Most of the answers were words or a short sentence or two, and some of them were a paragraph-sized passage. Table 1 illustrates the seven themes that were selected after the process of coding and indexing data.

The seven themes emerged from the older Koreans' comments $(\mathrm{N}=306): 1)$ maintaining a good physical health status, having no diseases or disabilities, maintaining a good mental health status, and no cognitive impairment such as dementia or Alzheimer's disease; 2) having a positive attitude toward the current life; 3) being active in spiritual and religious activity; 4) maintaining a good relationship with family and children; 5) being active in social interaction and positive socialization with others such as neighbors or other members in the adult health care center; 6) children's success; and 7) financial stability and independent life (mastery of life).

Table 2. Perceptions of Successful Aging among Older Korean Immigrants ( $\mathrm{N}=306)$

\begin{tabular}{lll}
\hline Successful Aging Themes & Frequency (\%) & Responses \\
\hline Maintaining a good physical & $120(39.2)$ & No diseases, disabilities, pains, or aches; no \\
and cognitive health status & major illness; no dementia; sleeping well; \\
& eating well; working out regularly; having a \\
& primary physician for regular health \\
& checkup; staying healthy physically and \\
& mentally;
\end{tabular}

Positive attitude toward the $69(22.5) \quad$ Appreciate what I have; always look at the 


\section{Macrothink $\Lambda$ Institute}

current life

Spiritual activity and 57 (18.6) religious life

Good relationship with 43 (14) family and children

Positive social interactions $40(13)$ and socialization

Children's successful life $\quad 35(11.4)$

Financial stability and $30(9.8)$ independent life (mastery of life) positive side; live happy; acceptance of current life status without complaining; acceptance of aging process and dying; enjoy every moment and each day; satisfied with life; feel and say that everything is going to be alright; be nice and flexible

Have a religion; live a religious life; attend worship services regularly; pray and meditate; sing hymns and gospels; read Bible or Buddhist texts; love your neighbors (like Jesus or Buddha); enjoy meeting with other members in church or temple

Enjoy being with family; give and receive love and attention; live close to family; visit, invite, or talk (over the phone) often with family; spend more time with family; not being a burden to family; no arguments, confrontations, conflicts, or disputes

Forgiving and being nice to everyone. Don't be greedy and act like adults; be generous and tolerate; be considerate to others; have regular interaction with others (to prevent a solitary life, and social isolation, or solitary death); joining a community activity.

Children's academic achievements; sending children to famous college/university; children's economic attainments; raise and support children to be professionals such as medical doctor, lawyer, professor, etc.; support them to be employed in big company

Being able to pay my bills; being able to pay for the miscellaneous for daily life; being able to pay for myself; feeling secure about financial matters; being able to invite family or friends for dinner or amusement; not being a financial burden to family and children 
4.2 Maintaining a Good Physical and Cognitive Health Status

One hundred twenty responses out of total 306 (39.2\%) indicated that maintaining a good physical and cognitive health condition, such as having no serious disease such as cancer, dementia, heart disease, Alzheimer's disease, diabetes, stroke, or other disabilities such as stroke paralysis, deafness, and blindness, etc., would be the most important factor to determine successful aging. The following excerpts are translated actual responses of the study participants.

Older female participant (OFP) 1: Living without severe disease like cancer or dementia and dying without any pain will be the best thing in our later life, and that would be a blessed and successful aging.

OFP 2: Don't get the dementia, it's not only losing you but also losing your family. This type of illness wears out final devotion.

Older male participant (OMP) 1: You don't have to be ill. If you were sick in your old age, that is a burden of your children; furthermore, you will be bothersome to your community and society, so don't be sick!

OMP 2: Maintain your health when you are healthy. If you lose your health when you are old, getting back to the previous status will be way more difficult than when you are younger, so you should be physically prepared before you are getting older.

OFP 3: Living well is a way to dying well. This is also a contribution for all.

OFP 4: I am scared of getting dementia. I don't want to be placed in a nursing home and dying alone. It will be extremely sad dying not knowing who I am and not remembering who I loved and who loved me.

The largest number of participants of this study on successful aging among older Korean immigrants responded that a physically and cognitively healthy ager would deserve to be a successful ager. Not being sick physically and cognitively seemed to be the essence of becoming a successful ager in terms of not being a burden to their spouse, family, or children. At this point, the older Korean immigrants' life style dependent on their family and children was indicated. Due to their language and cultural barrier, their children and family have been the most supportive system for their immigrant life (Choi \& Thomas, 2009). According to the Korean traditional culture of parents' infinite and unconditional sacrifice to their children, to some older Korean parents who participated in the study, their children's happiness, well-being, and successful life in this country is more valuable than their life (Min \& Moon, 2006). Therefore, to them, not being a burden to their family and minimizing their family's concern was a way of contribution and successful aging.

To maintain the healthy physical and cognitive conditions, the study participants mentioned regular exercise, adequate diet, quality sleep, reading, positive thinking, peaceful mind, meeting with friends, attending church, working or volunteering, participating in any social activities, etc. These were coded and indexed as maintaining a good physical and cognitive health status.

\subsection{Positive Attitude toward the Current Life}

Sixty nine responses out of 306 total $(22.5 \%)$ indicated that having positive attitudes toward their current life, having appreciation of their life, and being satisfied with their life would be 
the most important factor to determine successful aging. For example, it might be one kind of successful aging if older Korean immigrants were accepting their current situations even if they were neither healthy nor rich. It might be better if they could just accept their situation as it was. If they were able to understand and accept their children's life status, they would be happier even if they were not economically or educationally successful in this county. The following excerpts are translated actual responses of the study participants. Translated words mentioned alone or in sentences such as positive, appreciation, accept, satisfaction, adapt, accommodation, gratitude, grace, value, etc.' were coded and indexed as positive attitude toward the current life.

OFP 5: Being satisfied with my life and being thankful for what I have would be the way to reach successful aging.

OMP 3: As I am getting older, I have found that there are more valuable things than materials or secular success such as money, house, and car. Meaningful life, quality of life, and blessing others' lives would be more valuable and it would be leading us to successful aging.

OMP 4: Live a simple life and become an average man. There's nothing like being just a regular guy in the world. Don't even try to compare your life with others -- that is the beginning of disaster. Live your life and be thankful.

Traditionally, Koreans have been educated to respect others, accommodate changes in their environment, and obey the authority (Min \& Moon, 2006). To them, living alone with such discomforts as language, natural aging process, unexpected physical deteriorations after relocation, and poverty might be the options for them to accept as their destiny (Choi \& Thomas, 2009; Min \& Moon, 2006). They may think that it would be wiser to live with any type of inconveniences than to fight against them. Although their life status were miserable, if they were willing to accept and be satisfied with their current life, and be thankful for what they have now rather than complaining about what they do not have, they would believe that they could live a successful life in their later life.

In fact, a majority of the study participants expressed how appreciable they were for what they had because most of them were receiving governmental benefits such as Supplemental Security Income (SSI), Medicare, and Medicaid. Some of them received extra benefits such as Food Stamps and In-Home Supportive Service (IHSS). That meant they were placed under the extreme poverty line, and some of them expressed that this was shameful. However, most of the benefit recipients were thankful to the United States government for such reasons as they felt they were overpaid compared with what they had contributed to this country. Some participants did not have any history of working and paying taxes to this country. Other external environmental factors such as mild pacific weather in southern California and the culture of the Korea Town might provide them with more comfortable circumstances such as Korean restaurants, market, and translators than other places in this country.

One of the respondents (OFP 6) expressed her appreciation as follows: I lived such a miserable life. I experienced the Korean War when I was a child. I lost my husband in the Vietnam War, and then I immigrated to the States with my two sons. I made every effort to raise them, and worked diligently to make our American Dream come true. It seemed like we achieved it. I had a successful life in this country of opportunity. But soon, we experienced 
the L.A Riot and the Earthquake. We lost our business and house. However, we did not give up, and we stood up to all kinds of difficulties. We Koreans are people with a huge latent strength. Now our family is all good. The children are doing great in their positions. I believe I am blessed with all the benefits in this country. I am just satisfied with my current life, and I am undoubtedly living a successful life in my retirement years.

\subsection{Spiritual Activity and Religious Life}

Fifty seven respondents (18.6\%) indicated that having a religious life and attending regular spiritual activity would be important factors to lead to successful aging in later life. It has been well known that religious life and attending regular spiritual activities can provide a positive influence for older adults to acquire a better quality of later life throughout more social interactions and opportunities for socialization (Ellison, 1983; Lee, 2007; Adams, Leibbrandt, \& Moon, 2011; Lee \& Hwang, 2014; Wong, Yoo, \& Stewart, 2005). There was no exception for the older Korean immigrants who participated in this study.

OFP 7: Practicing of Zen meditation and listening to Buddha's instruction is the best enjoyment of my current daily life. This practice takes my anxiousness away, and makes my body and spirit healthy. I will continue this practice until the day I can no longer do it.

OFP 8: If you had lived a life that was led by Him, you lived a successful life, and you are aging successfully. We never know whether we lived a successful life or not, only God will judge our life.

OFP 9: We all have to live a pious life because longevity will be obtained through sincere and faithful life.

Koreans' religious practices have been based on a long historical background of Buddhism, Taoism, and Confucianism (Lee \& Hwang, 2014; Martin, 2005). The history of Catholicism and Christianity is relatively short in South Korea-120 years, more or less (Lee \& Hwang, 2014). The religion of these study participants was not included in the survey demographic questionnaire. This was one of the limitations and a crucial mistake of this study because, based on my dialogues with the study respondents, religious activity seemed to be a critical element of older Korean immigrants, and spirituality was one of the top ranked important factors of determining their successful aging. Maybe in the future research, a couple of yes or no questions about participating in religious and spiritual activities should be included, along with what types of religions they are practicing, such as Buddhism, Catholicism, or Christianity.

The majority of participants were involved with some type of religious practice at the time the research survey was conducted. The purposes of their devotion to religious activity varied. They solicited a blessed in this present life, or they sought for the eternal life. They prayed for their children's happiness, wellbeing, economic and educational success. They also used the religious activity as their coping mechanism and the pathway of social interactions. The churches and temples might be great resources for the older Korean immigrants to socialize. In reality, a large number of the Korean religious organizations provided great opportunities to share all kinds of information such as a community resource seminar for Medicare, Medicaid, Social Security, Supplemental Security Income, and US Citizenship. Some of the organizations invited medical doctors and nurses to provide educational presentations about 
how to prevent common geriatric health problems such as dementia, stroke, and heart disease. Also, local social workers were invited to speak about social work-related issues such as grand parenting and caregiver support. Some large-sized churches and temples established an educational, cultural, and social program in their organizations such as 'Silver School' and provided more constant and organized curriculums such as basic computer skills, English, arts $\&$ crafts, and exercises for prevention of geriatric health problems. The effectiveness of religious and spiritual activity could be explained in the following quote:

OFP 10: Attending church brings me a lot of benefit. I can meet my friends there, and I can share anything with them. I can find peace of mind there. I love singing gospel songs and hymns, and I love listening to my pastor's preaching. It touches me, it heals me, and it strengthens me. I believe my religion will take me to a good place after my death, and I believe I will meet all of my loved ones up there....

\subsection{Good Relationship with Family and Children}

Forty three respondents (14\%) indicated that maintaining a good relationship with family, especially children, would be an important factor for successful aging in later life. According to the discussion with the participants who provided this response, the main reason was their needs. For the older Korean immigrants who had a lack of English fluency, vulnerability, and cultural differences, family support, especially their children's assistance, was an absolute necessity (Lee, 2007; Lee \& Hwang, 2014; Wong, Yoo, \& Stewart, 2005).

OMP 5: In this immigrant life, the only people we can trust are our family. Who would be our backup when we need some help? In good times or bad times, we family should always be together, concerned about each other, and assist each other. Family should be the best value all the time.

OMP 6: Having someone nearby for support would be necessary when aging, and if the someone were a spouse or one of the family or children, that would be much better. My children are too busy to make their living. They have their own family. They don't have time for me. Sometimes I feel lonely and isolated even though I am living with my children.

OMP 7: Everybody needs somebody. Especially when you are sick and weak, you will need someone to take care of you. When you are physically and cognitively functioning well, you should make a good relationship with everyone nearby you. You should be nice to everyone, and you should be helpful to everyone; that will come back to you later on. I am pretty sure.

Moreover, the people receiving any types of governmental benefits such as Supplemental Security Income, Medicare, Medicaid, and Food Stamp, but having difficulty to read and understand English, tend to be embarrassed or anxious upon receiving a letter or document related to their benefits from the government. In this case, having someone to help them translate and explain the letter or document would be appreciated, and many of the participants wanted their children to play such a role for them.

OFP 11: My life is totally dependent on my children because I don't read and write anything in English. I don't have any financial resource but SSI. There are many documentations to complete to continue my SSI and Medicare and Medicaid. Whenever I receive a letter from them, I am highly anxious, and I can't even fall asleep due to too much worry. Even if my children said it's nothing and there's nothing to worry about, and that the benefits will be 
continued and nothing will affect my eligibility, I am always anxious. Without my children's help, who's going to be my support? I know social workers and nurses in this agency can help me, but I am still trust my family and children more. I am always thankful to have those benefits but, on the other hand, I am always nervous about losing them.

Also, some participants mentioned about dying in solitude or committing suicide in their later life. Especially the older adults who lived alone and were not often visited or contacted by their family or neighborhood were concerned about dying alone or being forgotten.

OFP 12: It will be the most miserable thing if I died in solitude and were found dead in a month or longer later on. That kind of news on TV or Newspaper makes me extremely depressed, and I feel like this can be happening to anyone including me. I am just hoping my daughter comes to see me as often as she can, and nothing bad occurs to me and her family.

\subsection{Positive Social Interactions and Socialization}

Another 40 respondents (13\%) indicated that positive social interactions and regular base socialization would be important factors for successful aging in later life. There were somewhat overlapping segments between the theme of good relationships with family and children, and social interactions with others (excluding family members), but the latter was highlighted in this section.

OMP 8: If you have someone who is willing to help you anytime, you are successful in this immigrant life. So, get along well with someone around you, and be sure that you are connected with someone, and keep interacting with others, friends, companions. That's an important factor for aging successfully in this country.

OMP 9: If you have at least one or two friends who will help you and to stand by your side when you are in trouble, especially when you are in difficult situations such as financial trouble or medical trouble, you lived a good life although you are not a successful, rich person or healthy person at the time. Because in this Korea Town, everyone lives for themselves; all are selfish. Sometimes they have to deprive themselves of what others have in order to make their living. In this community like a jungle, if you have anyone who can sacrifice for you, that means you lived a successful life, and if you are aging with such people who interact with you, you are aging successfully.

OMP 10: Relationship is the most important thing in one's life. Most of the problems are caused by unhealthy or broken relationships. Relationships include personal relations and social relations. We need to keep both relations well. See the 1992 Los Angeles Riot - if we had maintained a good relationship with the Latino community and the African American community, it would not have occurred in our community. We always need to be altruistic to others, especially to those who are in worse situations than us. That's the thing we need to consider to have a better life.

Immigrant life can be a desperate life for some (Lee, 2007). Immigrants to the United States expect the American Dream such as better economic opportunities, better quality of education for themselves or their children, and a more family-oriented life style; however, living in a foreign country as immigrants is not always pleasurable (Lee \& Hwang, 2014). In the case of ethnical minorities, it can be less secure and more stressful (Lee, 2007; Lee \& Hwang, 2014; Min \& Moon, 2006; Wong, Yoo, \& Stewart, 2005). Older Korean immigrants 
in the United States have struggled to achieve their American Dream. They dreamed of an economically prosperous life, their children's successful adaptation, and their own relaxed retirement, but they also had to face homesickness, loneliness, poverty, intermittent discrimination, relationship problems with their family and children, and health deterioration. In these situations, relationships with people around them might be as important as any other assets because broken or unhealthy relationships may cause them problems such as isolation, loneliness, or depression.

Good relationships with other ethnic communities or other immigrant population groups was also emphasized. The people who experienced the 1992 L.A Riot reminisced that the conflict was caused by a bad relationship with another ethnic group. They claimed that beautiful harmony with other immigrant/minority groups would be one of the most important factors to construct a healthy immigrant community in this country.

\subsection{Children's Successful Life}

Thirty five respondents $(11.4 \%)$ indicated that children's successful life such as educational achievement, economic attainment, or stable and steady immigrant life in the United States would be important factors for successful aging in their later life. It has been well known that Asian parents, for example, Korean, Chinese, Japanese, and Indian, are quite passionate about their children's education (Lee, 2007). They even sacrifice their life for their children's education, and they are willing to move to any place to provide a better educational environment for their children (Lee, 2007; Wong, Yoo, \& Stewart, 2005). They are eager to send their children to a better school, better college and university because they believe a highly ranked college/university will bring their children a higher chance to get a better job or become a professional with a high salary, such as medical doctor or lawyer (Lee, 2007; Wong, Yoo, \& Stewart, 2005).

OFP 13: Raising children is the best virtue of our cultural tradition. It does not only raise physically healthy people but also they should be raised as an essential member of their community. The best thing would be nurturing them to become high class ones or leaders.

Older Korean immigrants were not exceptions. They believed that parents' successful life can be measured by the level of their children's college/university and their professions. In sum, if their children are going to a top-notched school, or if they are employed by a big company/enterprise like Microsoft or Apple, or if they are working in legal or medical professions, this means their life was successful, and they are aging successfully.

OFP 14: The reason we immigrated to this country was just simple, to make a living and to send my kids to a good school. That's it. Now I have been widowed for years, but I am happy to see my children live a decent life here, and to see my grandchildren go to one of the greatest colleges in this country. I am a blessed one.

This is a unique component that was not included in any other successful aging studies except for the one study conducted in South Korea, Park and Chung's study on successful aging among low-income older people in South Korea (2008). This can be considered as an unusual characteristic of older Korean adults' important factors to determine successful aging. 
4.8 Financial Stability and Independent Life (Mastery of Life)

Of the total respondents, 30 indicated $(9.8 \%)$ that financial stability in later life and a financially independent life in retirement years would be important factors for successful aging. All of the participants for this study were receiving SSI at the time the survey was administered. Some of them verbally stated that they had some cash assistance from their children but for most of the participants, SSI was their only financial resource. Most of the participants expressed that they were always on a budget. Sometimes they felt shameful when they wished to spend some money for their grandchildren, but could not. They felt pity and felt that they were parsimonious.

OMP 11: If you're economically independent, you can raise your voice to your family or to others in your surroundings. If you have enough money, you can invite your children and grandchildren for dinner, and you can buy your grandchildren some toys. Most of all, you need some cash for yourself. You would be the one who needs cash to take care of yourself in your later life.

OMP 12: If you're not economically successful, how could you have a successful life in your retirement years? Even though you have any different type of success in your life, if you could not make a living at this time, how could you live your life successfully?

To become successful agers, older Korean immigrants indicated that they needed enough money to live an independent life. They put more emphasis on non-material components to determine successful aging such as health or children's successful life, but they also explained that they also could not live an independent life without assistance of capital.

\section{Discussion}

This study examined important predictors and factors to determine successful aging among older Korean immigrants and the population's perceptions toward successful aging. Seven significant factors influencing the population's aging successfully were identified: 1) maintaining a good physical health status, having no diseases or disabilities, maintaining a good mental health status, and having no cognitive impairment such as dementia or Alzheimer's disease; 2) having a positive attitude toward the current life; 3) being active in spiritual and religious activity; 4) maintaining a good relationship with family and children; 5) being active in social interaction and positive socialization with others such as neighbors or other members in the adult health care center; 6) children's success; and 7) maintaining financial stability and independent life (mastery of life).

One of the important findings was that the participants considered the positive attitude toward their current life status and acceptance of it as important factors and predictors to determine successful aging. Although the perceptions of older Korean immigrants in the United States toward successful aging such as the importance of maintaining physical and cognitive health were aligned with Rowe and Kahn's theory, there were different components such as their emphasis on positive attitude and acceptance of their life, family value, religious activity, and children's well-being.

According to the responses of the older Korean immigrants participating in this study, of all the important determinants of successful aging identified, a positive attitude toward their current life was the factor that they believed would make any older adult a successful ager. 
Whatever situation they might have, although physical and cognitive health was indicated as important, the older Korean immigrant's successful aging could be determined by his or her emphasis on a positive attitude toward their current life and religious life, which was more important than Rowe and Kahn's third component, active socialization.

The participants also emphasized their children's successful life and good relationship with them. The reason that older Korean immigrants wanted to maintain their healthy status, that is, the reason that they did not want to have a disease, physical disability, or dementia or Alzheimer's disease was that they did not want to be any burden to their family, especially to their children. In this immigrant life, older Koreans' perception of a successful life was living their own life and not bothering anyone, even their family and children.

All of the participants in this study were born in Korea and emigrated to the United States in their middle age to 65 years or older. English was their second language, and almost all of them maintained their language, meals, and other cultural values such as family-oriented customs and respect for the elderly as they used to do in Korea. Overall, the respondents were likely to have a positive attitude toward their immigrant life and were optimistic toward their successful aging although most of them were living below the poverty line, as all of the study participants were Social Supplemental Income recipients and some had some type of physical or cognitive deterioration.

One of the main limitations of this study was the lack of diversity in the sample. The sample was homogeneous, and their location was limited as well. Future research is needed to explore other ethnic older minorities and immigrants such as Latinos, African Americans, and other older adults who were born in other Asian countries.

Another limitation concerned the survey questions of the study. Questions should have been included to inquire about the participants' religion and their attendance at any types of spiritual activities. Future research is needed to explore how their religious values impact their successful aging in later life.

The study addressed that current rising issues in aging study such as positive aging (successful aging and productive aging), and meaningful life in baby boomer generation's retirement years were somewhat toward to mainstream populations. The study also intended to raise concerns about successful aging among older minorities and immigrants because they have been marginalized by aging research studies.

The findings of this study suggest the need for more attention to the populations of older immigrants/minorities, and innovations of community aging programs for those populations. Social workers need to be pioneers for developing and implementing these innovations, and will need to be cognizant that community aging services and interventions for successful aging should be ethically and culturally appropriate and in alignment with the needs of new generations of older populations consisting of unique individuals whose perspectives and experiences may vary. 


\section{Mll Macrothink}

International Journal of Social Work

ISSN 2332-7278

2018, Vol. 5, No. 2

\section{References}

Adams, K. B., Leibbrandt, S., \& Moon, H. (2011). A critical review of the literature on social and leisure activity and wellbeing in later life. Ageing Society, 31, 683-701. https://doi.org/10.1017/S0144686X10001091

Asian American Federation. (2003). Growing older: Asian American Elders in New York City. New York: Asian American Federation.

Atchley, R. C. (1989). A continuity theory of normal aging, The Gerontologist, 29(2), 183-190. https://doi.org/10.1093/geront/29.2.183

Baltes, P. B., \& Baltes, M. M. (1990). Psychological perspectives on successful aging: The model of selective optimization with compensation. In P. B. Baltes, \& M. M. Baltes (Eds.), Successful aging: Perspectives from the behavioral sciences. Cambridge, MA: Cambridge University Press. https://doi.org/10.1017/CBO9780511665684

Berry, J. W. (2003). Conceptual approaches to acculturation. American Psychological Association, 27, 17-37. https://doi.org/10.1037/10472-004

Cernin, P. A. (2009). A comparison of self-rated and objectively measured successful aging constructs in an urban sample of African American older adults. The Journal of Aging and Mental Health, 34(2), 89-102.

Choi, J. B., \& Thomas, M. (2009). Predictive factors of acculturation attitudes and social support among Asian immigrants in the USA. International Journal of Social Welfare, 18, 76-84. https://doi.org/10.1111/j.1468-2397.2008.00567.x

Chung, S., \& Park, S. (2008). Successful aging among low-income older people in South Korea. Aging and Society, 28, 1061-1074. https://doi.org/10.1017/S0144686X08007393

Creswell, J. (2009). Research design: Qualitative, quantitative, and mixed methods approaches. Thousand Oaks, CA: SAGE Publications, Inc.

Cumming, E., \& Henry, W. E. (1961). Growing old. New York, NY. Basic.

Depp, C. A., \& Jeste, D.V. (2006). Definitions and predictors of successful aging: A comprehensive review of larger quantitative studies. American Journal of Geriatric Psychiatry, 14(1), 6-20. https://doi.org/10.1097/01.JGP.0000192501.03069.bc

Dillaway, H. E., \& Byrnes, M. (2009). Reconsidering successful aging: A call for renewed and expanded academic critiques and conceptualization, Journal of Applied gerontology, 28(6), 702-722. https://doi.org/10.1177/0733464809333882

Ellison, C. W. (1983). Spiritual well-being: conceptualization and measurement. Journal of Psychology and Theology, 11(4), 330-340. https://doi.org/10.1177/009164718301100406

Ferri, C., James, I., \& Pruchno, R. (2009). Successful aging: definition and subjective assessment according to older adults, Clinical gerontologist, 32(4), 379-388. https://doi.org/10.1080/07317110802677302

Han, H., Kim, M., Lee, H. B., Pistulka, G., \& Kim, K.B. (2007). Correlates of depression in the Korean American elderly: Focusing on personal resources of social support. Journal of Cross Cultural Gerontology, 22, 115-127. https://doi.org/10.1007/s10823-006-9022-2

Hooyman, N. R., \& Kiyak, H. A. (2011). The resilience of elders of color. Social Gerontology (9th ed.). Boston, MA: Allyn \& Bacon. 
Jang, Y., Kim, G., \& Chiriboga, D. A. (2006). Health perception and depressive symptoms among older Korean Americans. Journal of Cross Cultural Gerontology, 21, 91-102. https://doi.org/10.1007/s10823-006-9026-y

Knight, T., \& Ricciardelli, L. A. (2003). Successful aging: Perceptions of adults aged between 70 and 101 years. International Journal of Aging and Human Development, 56(3) 223-245. https://doi.org/10.2190/CG1A-4Y73-WEW8-44QY

Larson, E. B., \& Phelen, E. A. (2002). "Successful aging": Where next? Journal of the American Geriatrics Society, $\quad$ 50, https://doi.org/10.1046/j.1532-5415.2002.t01-1-50324.x

Lee, K. H., \& Hwang, M. J., (2014). Private Religious Practice, Spiritual Coping, Social Support, and Health Status among Older Korean Adult Immigrants. Social Work in Public Health, 29(5), 428-443. https://doi.org/10.1080/19371918.2013.858234

Lee, Y. M. (2007). The immigration experience among elderly Korean immigrants. Journal of Psychiatric and Mental Health Nursing, 14, 403-410. https://doi.org/10.1111/j.1365-2850.2007.01098.x

Liang, J., \& Luo, B. (2012). Toward a discourse shift in social gerontology: From successful aging to harmonious aging, Journal of Aging Studies, 26(3), 327-334. https://doi.org/10.1016/j.jaging.2012.03.001

Maki, A. (2005). Relationship between spirituality and successful aging among older minority women, Dissertation Abstracts International, 66-07, 3975B.

McLaughlin, S. J., Connell, C. M., Heeringa, S. G., Li, L. W., \& Roberts, S. (2009). Successful aging in the United States: Prevalence estimates from a national sample of older adults. Journal of Gerontology: Social Sciences, 65B(2), 216-226. https://doi.org/10.1093/geronb/gbp101

Min, J. W. \& Moon, A. (2006). Older Asian Americans, Handbook of Social Work in Health and Aging. Oxford University Press.

Nagalingam, J. (2007). Understanding successful aging: A study of older Indian adults in Singapore, Care Management Journal, $\quad 8(1), \quad$ 18-25. https://doi.org/10.1891/152109807780494131

Oh, K. K., Zhou, Q., Kreps, G., \& Kim, W. (2014). The influences of immigration on health information seeking behaviors among Korean Americans and Native Koreans, Health Education \& Behavior, 41(2), 173-185. https://doi.org/10.1177/1090198113496789

Phelen, E. A., Anderson, L. A., LaCroix, A. Z., \& Larson, E. B. (2004). Older adults views of successful aging: How do they compare with researchers' definitions? Journal of the American Geriatrics Society, 52, 211-216. https://doi.org/10.1111/j.1532-5415.2004.52056.x

Rowe, J. W., \& Kahn, R. L. (1997). Successful aging. The Gerontologist, 37, 433-440. https://doi.org/10.1093/geront/37.4.433

Strawbridge, W. J., Wallhagen, M. I., \& Cohen, R. D. (2002). Successful aging and well-being: Self-rated compared with Rowe and Kahn. The Gerontologist, 42(6), 727-733. https://doi.org/10.1093/geront/42.6.727 
Tan, J., Ward, L., Ziaian, T. (2011). Comparing definitions of successful ageing: The case of Anglo-and Chinese Australians. Journal of Applied Psychology, 7(1), 15-21. https://doi.org/10.7790/ejap.v7i1.227

Tate, R., Lah, L., \& Cuddy, T. E. (2003). Definition of successful aging by elderly Canadian males: The manitoba follow-up study, The Gerontologist, 43(5), 735-744. https://doi.org/10.1093/geront/43.5.735

US Census Bureau. (2015). The 2015 Statistical Abstract. Retrieved from http://www.census.gov/compendia/statab/cats/population.html.

Victor, B. (2004). Successful aging and the Chinese-American elder, Dissertation Abstracts International, 65-12, 4434A.

\section{Copyright Disclaimer}

Copyright reserved by the author(s).

This article is an open-access article distributed under the terms and conditions of the Creative Commons Attribution license (http://creativecommons.org/licenses/by/3.0/). 